\title{
Comparação entre métodos para avaliação de empresas
}

\begin{abstract}
RESUMO
O objetivo deste trabalho consiste em analisar comparativamente os modelos de avaliação mais utilizados para calcular o valor venal justo de um negócio. Isso porque as reorganizações societárias tornaram-se frequentes nas últimas décadas, implicando muitas vezes redefinição de frações ou totalidades de empreendimentos. Para que tais negociações sejam possíveis, é necessário identificar o valor justo das partes envolvidas. Há diversos modelos de avaliação de empresas, e deles destacamse os do valor contábil, baseado no balanço patrimonial e do fluxo de caixa descontado. O trabalho é desenvolvido com base em investigação bibliográfica para identificar os modelos mais utilizados e fundamentar os conceitos abordados. Utiliza-se também a pesquisa documental para obter os dados necessários para análise e aplicação dos modelos de avaliação em uma situação real e com transação de venda concluída, permitindo comparar os resultados com o valor da negociação. Os resultados do estudo apresentam diferenças significativas entre os resultados dos modelos de avaliação empresarial e o valor de venda aceito pelo mercado, apesar de a literatura indicar que o valor final da empresa independe do modelo escolhido.
\end{abstract}

Palavras-chave: Avaliação de empresa. Valor contábil. Fluxo de caixa descontado.

Darci Schnorrenberger darcisc@gmail.com

Doutor em Gestão de Negócios e Professor da Universidade Federal de Santa Catarina

Mateus Gundlach Ambros

matheusgundlach@gmail.com

Graduado em Ciências Contábeis pela Universidade Federal de Santa Catarina

Valdirene Gasparetto

valdirenegaspareto@gmail.com

Doutora em Engenharia de Produção e Professora da Universidade Federal de Santa Catarina

Rogério João Lunkes

rogeriolunes@bol.com.br

Doutor em Engenharia de Produção e Professor da Universidade Federal de Santa Catarina 


\section{INTRODUÇÃO}

Nas últimas décadas, o mercado de aquisições, fusões, cisões e reestruturações organizacionais apresentou intensa atividade e, para que tais operações fossem possíveis, foi preciso definir o valor justo desses negócios. Ocorre que, frequentemente, o valor de venda esperado difere do valor apontado no patrimônio líquido da entidade, assunto que vem causando dúvidas ao longo dos séculos, conforme citam Martins e Assaf Neto (2000), ressaltando que a avaliação patrimonial de empresas tem provocado discussões acadêmicas e profissionais ao longo do tempo, confusões conceituais, críticas quanto à relevância e à utilidade da Contabilidade, conferências, artigos, etc.

A avaliação empresarial implica a análise aprofundada da empresa, do seu histórico de resultados, do seu mercado e, principalmente, de suas perspectivas evolutivas, pois ela será objeto de investimento por outra entidade. Como afirma Barreto (1999, p. 7), “o investimento [...] diz respeito à utilidade futura do bem para o seu possuidor e verifica-se em termos da geração de benefícios futuros".

Nesse processo, são consideradas variáveis objetivas e subjetivas que podem contribuir para o sucesso ou fracasso do negócio em avaliação e, consequentemente, do seu valor venal. Isso fez com que surgissem diversas e diferentes proposições metodológicas para encontrar referido valor.

Assim, por um lado, existe um modelo aceito e consagrado para evidenciar o valor patrimonial da empresa, que é o Balanço Patrimonial, mais especificamente, por meio do seu Patrimônio Líquido, que representa a riqueza dos donos do negócio. Por outro, são cada vez mais frequentes as contestações sobre sua real capacidade de mostrar o valor venal de uma empresa. Nesse contexto, emerge a questão que norteia este estudo: qual o modelo que melhor traduz o valor justo de venda de um negócio? Para responder a tal questão, o objetivo central do estudo consiste em analisar comparativamente os modelos de avaliação mais utilizados para calcular o valor venal justo de um negócio.

As etapas intermediárias da pesquisa consistem em buscar as bases teóricas que sustentam o estudo, identificar outros estudos já realizados acerca do tema e comparar os resultados com aqueles da situação real. Assim, o trabalho está estruturado em cinco seções, sendo esta, de introdução, a primeira. Na segunda seção, é apresentada a fundamentação teórica e, na terceira, os procedimentos metodológicos do trabalho. Na quarta seção, são apresentados os resultados da pesquisa, seguidos pela seção das considerações finais. Ao final são listadas as referências.

\section{FUNDAMENTAÇÃO TEÓRICA}

Nesta seção, abordam-se os aspectos teóricos que compõem o pano de fundo para a discussão do estudo a ser desenvolvido na seção 4. Apresentam-se, também, estudos com enfoque similar, para posterior comparação e cotejamento dos resultados.

\subsection{Aspectos conceituais envolvidos na avaliação empresarial}

A necessidade da aplicação da avaliação empresarial ou valuation ocorre em diversos momentos, convergindo todos no objetivo único de definir um valor justo para a negociação. Damodaran (2009) afirma que a avaliação empresarial é de grande utilidade na avaliação e gestão de carteiras, na análise de aquisições e em finanças corporativas. Goulart (1999, p. 58) reforça essa utilidade quando afirma que ela auxilia

\footnotetext{
[...] na compra ou venda de uma empresa; nos estudos de viabilidade de associações de interesses da empresa; numa expropriação legal; numa partilha entre herdeiros; na determinação das participações sociais; na fusão de duas ou mais empresas; na cisão de uma empresa no todo ou em partes; no aporte parcial em bens de uma empresa para outra; no aumento ou diminuição do capital; numa eventual conversão da dívida de um país em ações ou participações em empresas; na privatização de estatais e numa dissolução societária.
}

Cornell (1993, p. 7) explica que "o objetivo de uma avaliação é estimar o valor justo de mercado de uma empresa [...]". O resultado da avaliação não é, necessariamente, o preço de venda 
do empreendimento, mas pode ser entendido como um valor de referência para operações e negociações.

A avaliação empresarial pode evoluir em duas perspectivas. A primeira considera a hipótese de descontinuidade, desmanche ou liquidação da sociedade. A segunda leva em conta a continuidade da operação (MARTINS, 2000). Martins (1998) afirma que há duas formas de avaliar uma empresa em circunstâncias normais: (i) pelo valor de liquidação ordenada, ou seja, pelo que valem os ativos avaliados a preço de venda, diminuídos dos gastos para efetuar essa venda (comissão, impostos, transportes, etc.), e pelo valor necessário para saldar o passivo com terceiros; e (ii) pelo valor de funcionamento, que depende dos benefícios econômicos futuros que a empresa será capaz de gerar.

A primeira forma define o valor patrimonial da empresa. A fonte dessa informação é a Contabilidade e não deve sofrer ajustes para aproximar-se da realidade. A segunda forma define o valor econômico, considerando o potencial de geração de riqueza futura. Na visão voltada para o futuro, consideram-se riscos e expectativas do negócio, em que variáveis e projeções de resultado implicam o resultado final da avaliação. Assaf Neto (2010) entende que a definição do valor de uma empresa é uma tarefa complexa que requer coerência e rigor conceituais na formulação do modelo de cálculo. Existem diversos modelos de avaliação que possuem pressupostos e níveis variados de subjetividade.

Copeland, Koller e Murrin (2002) salientam que as operações de fusão e aquisição desempenham papel importante na realocação de recursos na economia internacional e na execução das estratégias corporativas. Dessas negociações participam diferentes atores, como contadores, advogados, consultores, investidores, bancos de investimentos e outros.

Damodaran (2009) destaca a importância da avaliação ao afirmar que ela deve desempenhar papel central na análise de aquisições. As partes devem estabelecer um valor justo para a empresaalvo antes de decidir aceitar ou rejeitar a proposta. Conforme o autor, há fatores que devem ser considerados na avaliação de uma aquisição como os efeitos da sinergia entre as empresas e sobre o valor resultante da reestruturação gerencial e operacional, e atentar para as expectativas do mercado e de rentabilidade.

O avaliador de empresas, pela importância do seu papel, pode sofrer pressão das partes envolvidas visando favorecer suas estratégias. Por isso, sua imparcialidade é fundamental para que o valor final seja um parâmetro válido para a negociação entre as partes.

\subsection{Modelos de avaliação empresarial}

Vários modelos de avaliação podem ser utilizados; todavia, o objetivo da avaliação e o objeto avaliado definem o melhor modelo de avaliação. Cunha e Lapeña (2007) afirmam que, independentemente dos modelos utilizados, o valor não será exatamente preciso, mas sim uma predição do valor de mercado. Martins (2000) e Penman (2005) esclarecem que, independentemente da quantidade de metodologias de avaliação existentes, todas devem convergir para um mesmo valor.

Fernandez (2001) classifica os principais modelos de avaliação de empresas em cinco grupos, conforme Quadro 1.

Quadro 1 - Principais métodos de avaliação de empresas

\begin{tabular}{|c|c|c|c|c|}
\hline $\begin{array}{c}\text { Balanço } \\
\text { patrimonial }\end{array}$ & $\begin{array}{l}\text { Demonstração } \\
\text { de resultado }\end{array}$ & Goodwill & $\begin{array}{c}\text { Fluxo de caixa } \\
\text { descontado }\end{array}$ & $\begin{array}{l}\text { Criação de } \\
\text { valor }\end{array}$ \\
\hline Valor contábil & Múltiplos & Clássico & Fluxo de caixa livre & EVA \\
\hline V. Cont. Ajustado & Valor dos lucros & $\begin{array}{l}\text { Simplificado da } \\
\text { União Européia }\end{array}$ & Dividendos & Lucro econômico \\
\hline Valor liquidação & Múltiplos de vendas & $\begin{array}{l}\text { Peritos Contábeis } \\
\text { Europeus }\end{array}$ & Equity cash flow & Cash value added \\
\hline \multirow[t]{2}{*}{ Valor substância } & P/EBITDA & Indireto & Capital cash flow & CFROI \\
\hline & Outros múltiplos & Outros & APV & \\
\hline
\end{tabular}

Fonte: Adaptado de Fernandez (2001, p. 3). 
Cunha e Lapeña (2007) realizaram pesquisa com 34 auditores independentes brasileiros e identificaram, com base numa escala Likert de 1 a 5 , a frequência de utilização dos modelos de avaliação empresarial na prática. Os resultados encontram-se no Gráfico 1.

Gráfico 1 - Modelos de avaliação mais utilizados pelos auditores independentes brasileiros

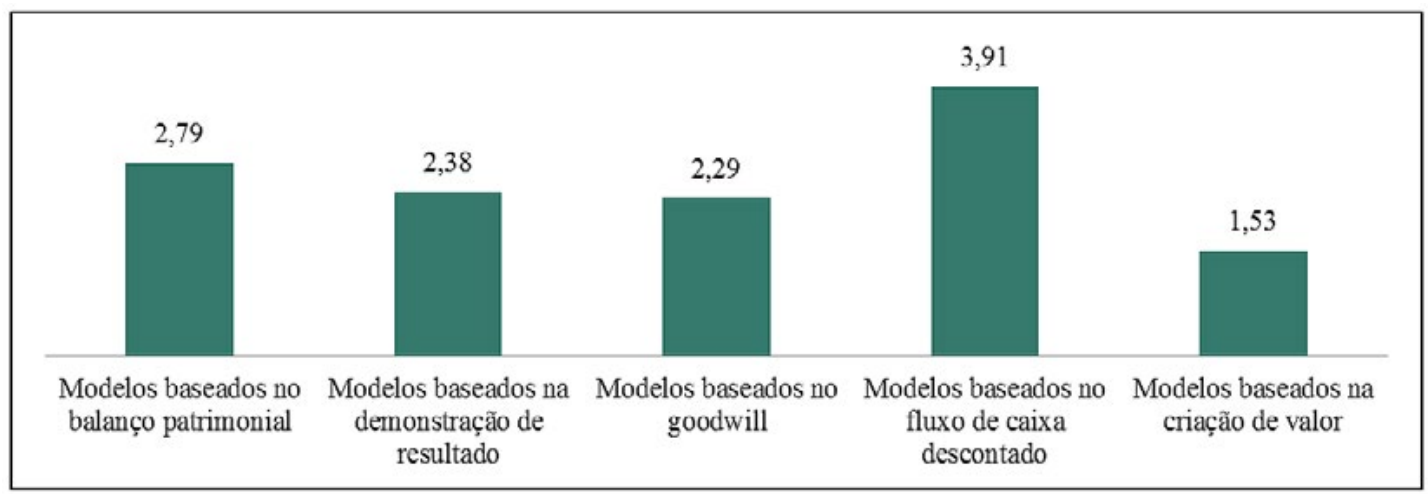

Fonte: Adaptado de Cunha e Lapeña (2007)

Martelanc et al. (2005) consultaram 29 profissionais da área de fusões e aquisições e private equity, dos principais bancos de investimento e consultorias financeiras do Brasil, e constataram que os modelos baseados no fluxo de caixa descontado são os mais utilizados, seguido pelos múltiplos ou avaliação relativa, e a terceira maior utilização coube aos modelos baseados no valor patrimonial ou contábil.

Assim, por serem os mais utilizados, os modelos baseados no valor contábil patrimonial e no fluxo de caixa descontado servirão de base para o estudo investigativo visando responder à questão central desta pesquisa.

\subsubsection{Método do valor contábil}

O modelo do valor contábil (MVC), também denominado como modelo de avaliação do valor contábil, modelo de avaliação patrimonial contábil ou modelo do balanço patrimonial, é o que mais conserva a informação contábil, pois não passa por nenhum ajuste ou adequação.

Apresenta como valor da empresa o próprio valor do patrimônio líquido obtido pela diferença entre os ativos e passivos exigíveis (ASSAF NETO, 2010).

A facilidade de obtenção dos valores e a compreensão associada à aceitação no mercado constituem-se nos pontos fortes do referido modelo de avaliação. Almeida et al. (2012) também destacam que a informação contábil é elemento fundamental na redução da assimetria informacional. Por outro lado, sua limitação reside no fato de que o balanço patrimonial pode ser considerado uma "fotografia" da situação financeira do negócio, que contempla um ponto de vista estático. Fernandez (2001) alerta para o fato de que ao adotar este tipo de procedimento, está sedo desconsiderada a possível evolução da empresa, o valor do dinheiro no tempo, o posicionamento de mercado, seus recursos humanos e intangíveis, assim como problemas de divulgação de informações organizacionais e/ou contratuais

O MVC, segundo Martins (2000), pode ser utilizado na avaliação de empresas que não tenham seus ativos com valores contábeis e de mercado muito distintos, assim como valores significativos de goodwill. Assim sendo, seu uso deve ser restrito por causa de observâncias da informação contábil.

\subsubsection{Método do fluxo de caixa descontado}

A metodologia do Fluxo de Caixa Descontado (FCD) valora um empreendimento com base na sua capacidade de geração de renda. Martins (2000) destaca a importância dessa leitura para identificação da viabilidade do negócio. Martelanc, Pasin e Pereira (2010) esclarecem que o valor da empresa está relacionado à sua capacidade de produção de fluxos de caixa positivos.

Dentre os modelos baseados no fluxo de caixa descontado, o fluxo de caixa livre da firma (FCLF) é o mais abordado por estudiosos como Damodaran (2009), Brealley e Miers (2000), e Brigham, Gapenski e Ehrhardt (2001), e é usado em diversas áreas, como a jurídica, por exemplo. 
Galdi, Teixeira e Lopes (2008) esclarecem que o FCLF considera apenas os valores provenientes das atividades operacionais, líquidos de tributos, diminuídos do caixa necessário aos investimentos em capital de giro e em ativos fixos. Esse fluxo igualmente é entendido como o fluxo de caixa operacional, pois considera apenas o fluxo gerado pela atividade-fim da empresa livre de financiamentos e empréstimos.

Referido fluxo utiliza dados históricos e de mercado para projetar as entradas e saídas de caixa, considerando a operação normal da organização, após a tributação, trazendo a valor presente esses fluxos financeiros a partir de uma taxa de desconto (DAMODARAN, 2009).

Essa taxa deve trazer embutido o custo de oportunidade do empreendimento (LUEHRMAN, 1997). Rappaport (2001) explica que o custo médio ponderado do capital costuma ser a taxa mais adequada para o desconto dos fluxos de caixa, sendo este, conforme Kobori (2011), o mais utilizado.

Martins (2000) destaca que o horizonte de projeção pode variar de acordo com as características do negócio e a disponibilidade de dados, sendo normalmente de cinco a dez anos.

Cerbasi (2003) define três elementos críticos para o uso do FCD: o fluxo de caixa projetado, o valor residual e a taxa de desconto. A definição ou o estabelecimento equivocado de qualquer uma dessas variáveis podem comprometer os resultados dessa metodologia.

Dentre os pontos fortes da metodologia estão a maior proximidade dos resultados com a realidade esperada, associado ao alto grau de aceitação e uso pelo mercado. Por outro lado, Lemme (2001) esclarece que as projeções e a consideração de expectativas futuras nos cálculos incluem arbitrariedade.

\subsection{Estudos com enfoque similar}

Os modelos e o processo de avaliação de empresas têm sido objeto de diversas pesquisas ao longo do tempo. Alguns trabalhos, como os de Fernandez (2001), Amaral (2009) e Lemme (2001), numa perspectiva mais teórica, revisaram e discutiram os principais métodos de avaliação de empresas, suas variações e aplicações.

Outros estudos buscaram identificar os métodos mais utilizados na prática. Cunha e Lapeña (2007) aplicaram questionários a trezentos auditores independentes brasileiros, de 34 empresas, e Soutes et al. (2008) aplicaram questionários aos profissionais de investimento associados à APIMEC. Ambos os trabalhos constataram que o FCD e o Valor Contábil encontram-se entre os métodos mais utilizados.

Diversos trabalhos, dentre os quais os de Miranda, Reis e Lemes (2006), Saurin, Costa Junior e Zilio (2007), Lima et al. (2010), e Duarte, Gomes e Ribeiro (2012), discutem aplicações do método do fluxo de caixa descontado em uma ou mais empresas, apresentando diferentes análises da aplicação, das variáveis empregadas nos métodos, do mercado dessas empresas e dos resultados.

Galdi, Teixeira e Lopes (2008), e Saurin, Miranda e Costa Junior (2009) comparam diferentes modelos de avaliação, como fluxo de caixa descontado versus modelo de Ohlson, e fluxo de caixa descontado versus lucro residual, respectivamente. Verificaram que o método do fluxo de caixa descontado foi o mais adequado na valoração de empresas.

Apesar dos muitos estudos, não se constatou nenhum que avaliasse, comparativamente, o valor de uma organização com base nos modelos do valor contábil e do fluxo de caixa livre da firma, como o que se pretende neste estudo, que permitirá identificar a diferença entre os modelos, bem como apontar o método que melhor representou o valor venal final do negócio.

\section{PROCEDIMENTOS METODOLÓGICOS}

Este artigo foi desenvolvido seguindo três etapas: (i) busca do arcabouço teórico visando identificar os modelos mais utilizados; (ii) coleta e projeção dos dados; e (iii) análise dos resultados.

A pesquisa documental e bibliográfica foi realizada, principalmente, no site de periódicos da CAPES. Referida etapa teve como foco as metodologias de avaliação de empresas com ênfase no FCLF e no MVC.

A coleta e a projeção dos dados primários foram realizadas com base no Balanço Patrimonial de 2012 e nas Demonstrações de Resultado dos Exercícios de 2009 a 2012 de uma empresa prestadora de serviços na área de automação e segurança localizada no município de Florianópolis (SC), e que, 
para fins de apresentação neste estudo, é denominada, de forma fictícia, como empresa Segurança. Por razões de sigilo, os dados utilizados neste estudo não são os reais, mas foram proporcionalizados para que não houvesse perda da simetria. Ou seja, apesar de não serem os dados reais, em proporções menores, representam uma empresa real.

Com base nos dados organizados e tabulados, procedeu-se à aplicação dos modelos de avaliação seguindo a metodologia correspondente a cada um. Segundo o FCLF, analisaram-se os dados históricos da empresa, que serviram de base para a projeção dos fluxos pelo período de cinco anos. Calculou-se a taxa de desconto dos fluxos pelo do CMPC e o valor residual da operação, chegando ao resultado referente ao modelo. O uso do MVC implicou a análise do BP para extração do resultado sem ajustes, utilizando, assim, a informação contábil.

Por fim, compararam-se os resultados obtidos, tomando por base os modelos, com o valor de venda da empresa. Os resultados obtidos também foram comparados com resultados de outras empresas.

\section{ESTUDO DE CASO}

Nesta etapa, apresenta-se a avaliação da empresa Segurança com base nos modelos do Valor Contábil e do Fluxo de Caixa Livre da Firma. Em seguida, comparam-se os resultados entre si e com os de outros estudos.

\subsection{Método do valor contábil}

No cálculo do valor da empresa Segurança com o Modelo do Valor Contábil, utilizou-se o Balanço Patrimonial de 31 de dezembro de 2012, que consta na Tabela 1.

Tabela 1 - Balanço Patrimonial em 31 de dezembro de 2012

\begin{tabular}{lr|lr}
\hline \multicolumn{4}{c}{ Balanço Patrimonial findo em $\mathbf{3 1}$ de dezembro de 2012 (em R\$ mil) } \\
\hline ATIVO & $\mathbf{3 9 4 , 1 7}$ & PASSIVO & $\mathbf{3 9 4 , \mathbf { 1 7 }}$ \\
Ativo Circulante & $\mathbf{2 9 6 , 1 7}$ & Passivo Circulante & $\mathbf{9 3 , 2 0}$ \\
Disponível & 237,52 & Empréstimos e Financiamentos & 14,02 \\
Clientes & 41,93 & Fornecedores & 33,91 \\
Outros Créditos & 1,55 & Obrigações Tributárias & 4,56 \\
Estoque & 15,17 & Obrigações Trabalhistas e Previdenciárias & 40,18 \\
Ativo não Circulante & 98,00 & Outras Obrigações & 0,53 \\
Outros Créditos & 4,90 & Passivo não Circulante & 22,30 \\
Imobilizado & 93,10 & Empréstimos e Financiamentos & 22,30 \\
& & Patrimônio Líquido & 278,67 \\
& & Capital Social & 200,20 \\
& & Resultados a Destinar & 78,47 \\
\hline
\end{tabular}

Fonte: Dados da pesquisa (2013)

Observando as diretrizes do modelo do valor contábil tem-se que valor da empresa $=$ ativos contábeis - passivos exigíveis contábeis; logo, valor da empresa $=\mathrm{R} \$ 394.168,30-\mathrm{R} \$ 115.500,59=$ $\mathrm{R} \$ 278.667,71$.

\subsection{Cálculo do fluxo de caixa livre da firma}

O FCLF foi aplicado considerando-se o BP de 2012 e a DRE dos anos de 2009 a 2012. Com base nesses dados, projetaram-se os fluxos de caixa livres pelo período de cinco anos (de 2013 a 2017) e, juntamente com o período de perpetuidade, procedeu-se ao desconto desses valores, considerando a taxa de desconto.

\subsubsection{Taxa de desconto}


A taxa de desconto, conforme recomendado pela literatura, foi definida com base no Custo Médio Ponderado de Capital (CMPC), que considera a participação percentual de fontes de recursos de terceiros e próprios versus os custos.

Para definição do CMPC, considerou-se a estrutura de capital da empresa, que inclui as fontes de recursos de médio e longo prazos (MARTINS, 2000). Na data do BP, 7,4\% dos capitais totais eram de terceiros e $92,6 \%$, próprios.

O capital de terceiros era proveniente de uma única operação de empréstimo para capital de giro obtida em 2011 ao custo de $18,68 \%$ a. a. livre de efeitos tributários. O custo desse capital é a taxa de captação de recursos externos da empresa.

O custo de capital próprio foi obtido com o modelo Capital Asset Pricing Model (CAPM), elaborado por Willian Sharpe, que determina ser o retorno exigido pelo acionista igual ao retorno dos investimentos sem risco acrescido de um prêmio pelo risco (MARTINS, 2000). Para composição do mencionado cálculo, tem-se:

$\mathrm{Ke}=\mathrm{Rf}+\beta \times(\mathrm{Rm}-\mathrm{Rf})$

Onde:

$\mathrm{Ke}=$ custo do capital próprio, retorno exigido pelo acionista;

$\beta=$ coeficiente beta, risco sistemático;

$\mathrm{Rf}=$ retorno dos investimentos sem risco;

$\mathrm{Rm}=$ retorno dos investimentos de mercado.

O coeficiente beta $(\beta)$ mede o risco sistemático do título, ou seja, relaciona as variações de um título e as da carteira de mercado. Para a determinação do custo de capital próprio, o beta foi considerado igual a 1,0, pois a organização estudada tem seu capital social fechado e, conforme Assaf Neto, Lima e Araújo (2008), um ativo com beta igual a 1,0 terá um retorno na mesma direção e intensidade do retorno médio da carteira de mercado.

Como retorno dos investimentos sem risco (Rf), foi considerada a rentabilidade aritmética média da poupança de 2009 a 2012, resultando em 18,15\% no período, enquanto o retorno dos investimentos de mercado $(\mathrm{Rm})$ foi obtido por meio da rentabilidade aritmética média do IBOVESPA no mesmo período, de 6,99\%.

Considerando tais valores, o custo do capital próprio utilizado neste estudo é de:

$\mathrm{Ke}=18,15 \%+1,0 \times(6,99 \%-18,15 \%)=18,15 \%$ ao ano.

Com base nesses dados e utilizando a equação do CMPC chega-se ao seguinte valor: CMPC = $(7,41 \% \times 23,76 \%)+(92,59 \% \times 18,15 \%)=18,66 \%$ ao ano.

\subsection{Previsão de desempenho}

A previsão dos fluxos de caixa futuros da empresa com base nas taxas de crescimento é necessária na elaboração da avaliação. As taxas de crescimento para a empresa Segurança foram definidas tomando-se por base dados históricos e básicos, como indica Damodaran (2009). As DREs realizadas e projetadas são apresentadas na Tabela 2. 
Tabela 2 - Demonstração do resultado dos exercícios realizados e projetados

\begin{tabular}{|c|c|c|c|c|c|c|c|c|c|}
\hline \multirow{2}{*}{ DRE (em R\$ mil) } & \multicolumn{4}{|c|}{ Realizada } & \multicolumn{5}{|c|}{ Projetada } \\
\hline & 2009 & 2010 & 2011 & 2012 & 2013 & 2014 & 2015 & 2016 & 2017 \\
\hline $\begin{array}{l}\text { Receita bruta de vendas e } \\
\text { serviços }\end{array}$ & 931,64 & 991,11 & $1.065,71$ & $1.122,24$ & $1.194,11$ & $1.270,59$ & $1.351,97$ & $1.438,56$ & $1.530,69$ \\
\hline (-) Deduções da receita bruta & $-75,38$ & $-76,16$ & $-78,14$ & $-79,28$ & $-80,63$ & $-82,00$ & $-83,39$ & $-84,81$ & $-86,25$ \\
\hline Receita líquida & 856,26 & 914,95 & 987,57 & $1.042,95$ & $1.113,48$ & $1.188,59$ & $1.268,57$ & $1.353,74$ & $1.444,44$ \\
\hline (-) Custo das mercadorias vendidas & 385,95 & 411,28 & 438,93 & 468,57 & 499,87 & 533,26 & 568,88 & 606,88 & 647,41 \\
\hline (-) Custo dos serviços prestados & 325,56 & 339,55 & 369,25 & 380,12 & 400,37 & 421,71 & 444,18 & 467,85 & 492,78 \\
\hline Lucro bruto & 144,75 & 164,11 & 179,38 & 194,27 & 213,24 & 233,62 & 255,51 & 279,02 & 304,24 \\
\hline (-) Despesas operacionais & 58,23 & 63,55 & 69,41 & 75,06 & 81,72 & 89,00 & 96,93 & 105,59 & 115,05 \\
\hline Despesas com vendas & 23,31 & 26,40 & 29,13 & 31,48 & 34,80 & 38,48 & 42,54 & 47,03 & 51,99 \\
\hline Despesas administrativas & 34,92 & 37,15 & 40,28 & 43,58 & 46,92 & 50,52 & 54,39 & 58,56 & 63,06 \\
\hline Receitas financeiras & 1,86 & 1,98 & 2,17 & 2,33 & 2,51 & 2,71 & 2,92 & 3,15 & 3,39 \\
\hline (-) Despesas financeiras & 3,35 & 3,70 & 3,85 & 4,02 & 4,27 & 4,54 & 4,83 & 5,13 & 5,46 \\
\hline Resultado operacional líquido & 85,03 & 98,84 & 108,29 & 117,52 & 129,75 & 142,79 & 156,67 & 171,44 & 187,13 \\
\hline (-) Despesas não operacionais & 1,18 & 1,33 & 1,54 & 1,71 & 1,94 & 2,19 & 2,48 & 2,81 & 3,18 \\
\hline Receitas não operacionais & 4,12 & 4,24 & 4,75 & 4,98 & 5,31 & 5,66 & 6,03 & 6,43 & 6,85 \\
\hline Resultado antes do IR e CSLL & 87,97 & 101,75 & 111,50 & 120,79 & 133,13 & 146,26 & 160,23 & 175,06 & 190,81 \\
\hline Lucro líquido do exercício & 87,97 & 101,75 & 111,50 & 120,79 & 133,13 & 146,26 & 160,23 & 175,06 & 190,81 \\
\hline
\end{tabular}

Fonte: Elaborada pelos autores (2013).

O período de projeção escolhido para o período foi de cinco anos em virtude da estabilidade dos fluxos históricos e projetados apresentados pela empresa, pois, conforme Copeland, Koller e Murrin (2002), "todas as abordagens ao valor contínuo [perpetuidade], baseiam-se na premissa de desempenho estável. O período de previsão explícita deve ser longo o bastante para que a empresa tenha chegado ao estado de estabilidade no fim dele".

\subsubsection{Fluxo de caixa livre da firma}

Com base na projeção dos resultados, calculou-se o FCLF, conforme Tabela 3.

Tabela 3 - Demonstração do cálculo do FCLF

\begin{tabular}{lrrrrr}
\hline FCLF (em R\$ mil) & $\mathbf{2 0 1 3}$ & $\mathbf{2 0 1 4}$ & $\mathbf{2 0 1 5}$ & $\mathbf{2 0 1 6}$ & $\mathbf{2 0 1 7}$ \\
\hline $\begin{array}{l}\text { (=) Lucro Operacional Líquido menos Imposto } \\
\text { Ajustado }\end{array}$ & 133,13 & 146,26 & 160,23 & 175,06 & 190,81 \\
(+) Depreciação e Amortização & 34,06 & 36,70 & 39,54 & 42,60 & 45,90 \\
(-) Variação do Capital de Giro & 20,31 & 21,89 & 23,58 & 25,41 & 27,38 \\
(-) Investimentos em Ativos Imobilizados & 42,60 & 45,90 & 49,45 & 53,28 & 57,40 \\
\hline (=) Fluxo de Caixa Livre da Firma & $\mathbf{1 0 4 , 2 7}$ & $\mathbf{1 1 5 , 1 7}$ & $\mathbf{1 2 6 , 7 3}$ & $\mathbf{1 3 8 , 9 8}$ & $\mathbf{1 5 1 , 9 3}$ \\
\hline
\end{tabular}

Fonte: Elaborado pelos autores (2013).

O FCLF gerado no período de 2013 a 2017 foi descontado por uma taxa baseada no custo médio ponderado de capital de $18,66 \%$ ao ano. A soma desses fluxos descontados resulta num valor de R\$ 380,23 mil para esse período.

A partir do fluxo estabilizado do quinto ano de projeção, calculou-se o valor da perpetuidade considerando a mesma taxa de desconto de $18,66 \%$ ao ano e uma taxa de crescimento de $2,5 \%$ ao ano, que corresponde à previsão de crescimento do PIB para 2013, segundo o Relatório Focus emitido pelo Banco Central do Brasil, em novembro de 2013. Por sua vez, a soma dos fluxos gerados no período de perpetuidade resultou em $\mathrm{R} \$ 963,76$ mil (BRASIL, 2013).

O resultado com a soma dos fluxos do período explícito e com a soma dos fluxos no período de 
perpetuidade obtido está descrito na Tabela 4.

Tabela 4 - Resultados da soma dos fluxos e da soma da perpetuidade

\begin{tabular}{lc}
\hline \multicolumn{2}{c}{$\begin{array}{l}\text { Resultados da soma dos fluxos e da soma da per- } \\
\text { petuidade (em } \mathbf{R} \mathbf{\$} \text { mil) }\end{array}$} \\
\hline Soma dos Fluxos & 380,23 \\
Soma da Perpetuidade & 963,76 \\
\hline VPL & $\mathbf{1 . 3 4 3 , 9 9}$ \\
\hline
\end{tabular}

Fonte: Elaborado pelos autores (2013)

O Valor Presente Líquido (VPL) representa o valor presente dos fluxos de caixa gerados no período explícito e no período de perpetuidade após aplicação das devidas taxas de desconto e, para a empresa Segurança, resultou no valor de $R \$ 1.343,99$.

\subsection{Comparação entre os resultados obtidos}

A empresa Segurança teve $100 \%$ de suas cotas sociais vendidas em fevereiro de 2013 por R\$ 1,120 milhão de reais (Tabela 5). Esse valor de venda foi proporcionalizado com o mesmo índice utilizado no ajuste das informações financeiras e contábeis para manutenção da confidencialidade dos números e da operação de venda.

Os valores atribuídos à empresa Segurança pelos modelos de avaliação estudados foram diferentes, tanto considerando para o modelo do fluxo de caixa livre da firma apenas a soma dos fluxos do período explícito de projeção, como considerando adicionalmente o valor da perpetuidade.

Tabela 5 - Comparação entre o valor contábil e a soma dos fluxos

\begin{tabular}{l|r|r}
\hline Resultados (em R\$ mil) & Valor & $\%$ \\
\hline Valor Contábil & 278,67 & $100,00 \%$ \\
\hline Soma dos FCLFs & 380,23 & $136,44 \%$ \\
\hline Diferença & 101,56 & $36,44 \%$ \\
\hline
\end{tabular}

Fonte: Elaborado pelos autores (2013).

Ao considerar como base os valores constantes no Balanço Patrimonial e compará-los com os obtidos pela soma dos fluxos de caixa livre da firma projetados, percebe-se uma diferença de $\mathrm{R} \$$ 101,56 mil entre ambos, ou seja, um valor $36,44 \%$ superior ao contábil.

Essa diferença fica ainda maior quando se inclui no cálculo a soma da perpetuidade, conforme Tabela 6.

Tabela 6 - Comparação entre valor contábil e VPL

\begin{tabular}{l|r|r}
\hline Resultados (em R\$ mil) & Valor & $\%$ \\
\hline Valor Contábil & 278,67 & $100,00 \%$ \\
VPL & $1.343,99$ & $482,29 \%$ \\
Soma dos Fluxos & 380,23 & $136,44 \%$ \\
Soma da Perpetuidade & 963,76 & $345,84 \%$ \\
\hline Diferença & $1.065,32$ & $382,29 \%$ \\
\hline
\end{tabular}

Fonte: Elaborado pelos autores (2013).

Na perspectiva de adição do valor da perpetuidade ao valor da soma dos fluxos, a diferença aumenta e o valor contábil passa a corresponder a 20,73\% do VPL da empresa Segurança.

Nas duas visões, o resultado obtido pelo fluxo de caixa descontado é maior, revelando a lacuna existente entre o valor contábil e o valor econômico da empresa. A segunda opção de análise também revela o peso da consideração do valor da perpetuidade na avaliação de um empreendimento.

Na Tabela 7, é possível comparar os resultados dos dois modelos de avaliação com o preço de venda efetivamente realizado. 
Tabela 7 - Comparação entre o VPL, o valor contábil e o valor de venda

\begin{tabular}{l|r|r}
\hline Análise da venda (em R\$ mil) & Valor & $\%$ \\
\hline Valor Contábil & 278,67 & $24,88 \%$ \\
VPL & $1.343,99$ & $120,00 \%$ \\
\hline Valor de venda realizado & $1.120,00$ & $100,00 \%$ \\
\hline
\end{tabular}

Fonte: Elaborado pelos autores (2013).

$\mathrm{Na}$ Tabela 6, fica evidente a distância entre os valores obtidos por meio dos modelos estudados e o valor de venda realizado. O valor contábil representa aproximadamente $25 \%$ do valor de venda realizado, deixando evidenciada sua insuficiência para atender a situações dessa natureza. Por outro lado, o VPL, mesmo trazendo valores $20 \%$ superiores aos praticados, mostrou-se muito mais próximo e apropriado para a situação.

\subsection{Comparação com os resultados obtidos por outros autores}

A diferença entre os valores estimados pelos modelos embasados nas informações contábeis e o baseado no fluxo de caixa descontado é discutida por diversos pesquisadores. Martins (2000) e Penman (2005) afirmam que independentemente do modelo de valuation utilizado, todos devem resultar num mesmo valor. Isso, no entanto, não se confirmou neste estudo.

Martelanc et al. (2005) entendem que o valor contábil é conhecido e facilmente identificável. Entretanto, Cornell (1993) afirma que as informações contábeis raramente apontam um valor razoável para o empreendimento, e Mendoza (2008) ressalta que a contabilidade considera valores históricos para os investimentos e resultados apresentados pela empresa sem que sejam corrigidos monetariamente. Por isso, Helfert (2000) conclui que o uso da informação contábil para avaliação econômica de empresas geralmente é deficitário. De fato, os resultados do estudo corroboram com a afirmação de Helfert (2000), pois o valor contábil evidenciou apenas $24,88 \%$ do valor venal realizado.

Sobre o FCD, Van Horne (1995) destaca que análises tradicionais do VPL podem causar a subestimação deste, pois não captam possíveis benefícios de flexibilidade operacional e outros fatores estratégicos. Todavia, Copeland, Koller e Murrin (2002) argumentam que o valor intrínseco baseia-se nas expectativas de fluxos de caixa futuros e não por aquilo que a empresa fez no passado e, muito menos, pelo custo de seu ativo. Os resultados deste estudo mostraram que os valores do VPL foram superiores aos efetivamente praticados, contrariando a afirmação de Van Horne (1995).

Confirmou-se, também, neste estudo a correção da afirmativa de Martins (2000, p. 269) de que o "modelo de avaliação patrimonial contábil pode ser utilizado por empresas cujos ativos mensurados pelos princípios contábeis não divergem muito de seus valores de mercado e que não possuem um goodwill significativo". Considerando os arranjos organizacionais atuais, fica claro de que a utilidade do referido método para valorar uma empresa está cada vez mais distante da realidade, pois os aspectos intangíveis estão cada vez mais presentes e decisivos para o sucesso das organizações.

Alguns estudos comparam os valores obtidos por cada um desses métodos e o valor aceito pelo mercado. Cunha e Lapeña (2007), por exemplo, salientam que a diferença entre o valor calculado no processo de avaliação de empresas e o valor do patrimônio é de mais de $50 \%$. O presente estudo demonstra que a diferença entre o VPL total do empreendimento e o seu valor contábil guarda um descolamento de $79 \%$. Kaplan e Ruback (1995) ressaltam que a avaliação pelo método do FCD apresenta distorções inferiores a $10 \%$ em relação aos valores de mercado de transações completadas sobre companhias de capital aberto. Neste estudo, o desvio foi de $20 \%$ entre tais valores.

Por fim, Fairfield (1994) defende que uma mescla de metodologias baseadas em lucro e valores contábeis pode ser utilizada. Ottosson e Weissenrieder (1996), e Rosa Júnior (2003) acreditam que o avaliador precisa de uma metodologia de avaliação de empresa que seja a ligação entre seu desempenho histórico e sua avaliação como opção de investimento.

\subsection{Análise das divergências metodológicas entre os modelos}

Dentre as diferenças existentes nas fontes de informação e nas perspectivas de análise entre os métodos do valor contábil e o fluxo de caixa descontado, pode-se destacar que a avaliação empresarial pode evoluir em duas perspectivas (MARTINS, 2000). O método do valor contábil 
considera a empresa de forma estática, enquanto o método do fluxo de caixa descontado leva em conta a continuidade da operação.

As demonstrações contábeis igualmente não evidenciam valores adequados para os ativos intangíveis das empresas e que, em alguns casos, têm valor significativo. Por exemplo, o capital humano da empresa Segurança está subestimado em seus demonstrativos contábeis, pois ela é prestadora de serviços complexos e conta com profissionais altamente qualificados para o cumprimento de suas atividades. Essa limitação, apesar de não ser contemplada pelo método do FCD, de alguma forma acaba atenuada com a inclusão das variáveis de expectativas de retornos futuros e da perpetuidade do negócio.

A utilização dos demonstrativos contábeis no processo de valuation de maneira pura pode ser prejudicial, porém, sua utilidade consiste no provimento de informações de desempenho histórico que leva os modelos a serem mais próximos à realidade.

\section{CONSIDERAÇÕES FINAIS}

Apesar de a literatura sinalizar que o valor final de um empreendimento independe do método escolhido, na prática constatou-se que as diferenças existem e são significativas entre os dois métodos estudados. O valor contábil representou aproximadamente $25 \%$ do valor de venda da empresa, resultado que certamente deve levar os estudiosos da área a refletir a respeito das limitações desse método ou sua real utilidade para tal finalidade. Por seu turno, o valor final obtido pelo FCD, diferentemente do previsto na literatura, superou o valor final de venda em $20 \%$, estando, portanto, mais próximo do preço final praticado neste caso.

Os resultados encontrados neste estudo serviram para mostrar que o método empregado para avaliar o valor de uma organização interfere, significativamente, no valor final. Constatou-se que um método aproximou-se mais do valor venal final do que o outro, mas ambos têm fragilidades e carecem de mais pesquisas e discussões, visando aperfeiçoá-los. Talvez a discussão não deva ser no sentido de identificar qual o melhor método, e sim em encontrar os pontos fortes e fragilidades de cada um e rumar para a complementariedade entre métodos, não a exclusividade.

Este estudo foi realizado em uma situação real; logo, as constatações e conclusões são reais. Para confirmar ou contestar estes achados, outros estudos poderiam ser realizados em empresas de outros setores da economia a fim de verificar se a estrutura de capital ou o tipo de atividade exercem alguma influência no resultado final. Poderia também ser realizada uma pesquisa simultânea em dois tipos de empresas, sendo uma de capital intangível intensiva e outra tangível intensiva.

\section{COMPARISON OF METHODS FOR ASSESSMENT OF COMPANIES}

\section{ABSTRACT}

The objective of this paper is to identify and analyze comparatively the most often used models of valuation to calculate the fair market value of a business. Corporate reorganizations have become common in recent decades, often resulting in redifining part or the whole value of ventures. For such negotiations to be possible it is necessary to identify the fair value of the parties involved. There are many business valuation models and among these is the book value based on the balance sheet and discounted cash flow. This research is based on literature search to identify the most commonly used models and explain the concepts covered in the process. Documentary research is also used to obtain the necessary data for analysis and application of valuation models in a real situation and the completed sales transaction. This enabled the comparasion of the results with the trading value. The results show significant differences between the results of the model applied for company valuation and the sales value accepted by the market, although literature indicates that the final value of the company does not depend on the model chosen to establish its worth.

Keywords: Business Valuation. Book Value. Discounted Cash Flow. 


\section{REFERÊNCIAS}

ALMEIDA, José Elias Feres de et al. Análise dos Modelos de Avaliação Residual IncomeValuation, Abnormal EarningsGrowth e Fluxo de Caixa Descontado Aplicado às Ofertas Públicas de Aquisição de Ações no Brasil. Revista de Contabilidade e Organizações, São Paulo, v. 6, n. 16, p. 3-19, nov. 2012.

AMARAL, A. C. do. Metodologias de avaliação de empresas: teoria e prática. Revista Integração, São Paulo, ano XV, n. 56, p. 7-12, jan./mar. 2009. Disponível em: <ftp://ftp.usjt.br/pub/revint/07_56. pdf>. Acesso em: 6 jan. 2014.

ASSAF NETO, Alexandre. Finanças Corporativas e Valor. 5. ed. São Paulo: Atlas, 2010.

ASSAF NETO, Alexandre; LIMA, Fabiano Guasti; ARAÚJO, Adriana Maria Procópio de. Uma proposta metodológica para o cálculo do custo de capital no Brasil. Revista de Administração, São Paulo, v. 43, n. 1, p. 72-83, mar. 2008.

BARRETO, A. C. P. M. Avaliação econômica financeira de marcas: um estudo de caso sob a perspectiva do modelo de fluxo de caixa descontado. Dissertação (Mestrado em Administração) Universidade de São Paulo, São Paulo, 1999.

BRASIL. BANCO CENTRAL DO BRASIL. Focus: Relatório de Mercado. [2013]. Disponível em: <http:// www.bcb.gov.br/pec/GCl/PORT/readout/R20131129.pdf>. Acesso em: 2 jan. 2013.

BREALLEY, R. A.; MYERS, S. C. Principles of corporate finance. 5. ed. New York: McGraw-Hill, 2000.

BRIGHAM, E. F.; GAPENSKI, L. C.; EHRHARDT, M. C. Administração financeira: teoria e prática. São Paulo: Atlas, 2001.

CERBASI, Gustavo Petrasunas. Metodologias para determinação do valor das empresas: uma aplicação no setor de geração de energia elétrica. Dissertação (Mestrado em Administração) Universidade de São Paulo, São Paulo, 2003.

COPELAND, Tom; KOLLER, Tim; MURRIN, Jack. Avaliação de empresas - valuation: calculando e gerenciando o valor das empresas. São Paulo: Makron Books, 2002.

CORNELL, B. Corporate Valuation: Tools for Effective Appraisal and Decision Making. New York: Business One Irwin, 1993.

CUNHA, Darliane Ribeiro; LAPEÑA, Jose Angel Anson. Análisis de los modelos de valoración utilizados em la práctica: Un estúdio con auditores independientes brasileños. Revista Universo Contábil, Blumenau, v. 3, n. 3, p. 123-138, dez. 2007.

DAMODARAN, Aswath. Avaliação de Investimentos: Ferramentas e Técnicas para a Determinação do Valor de Qualquer Ativo. 2. ed. Rio de Janeiro: Qualitymark, 2009.

DUARTE, Sérgio Lemos; GOMES, Thiago Simões; RIBEIRO, Karem Cristina de Sousa. Avaliação Empresarial Contábil: Uma análise no setor sucroalcooleiro. Revista Razão Contábil \& Finanças, Fortaleza, v. 3, n. 2, p. 76-90, dez. 2012.

FAIRFIELD, Patricia M. P/E, P/B and the present value of future dividends. Financial Analysts Journal, New York. v. 50, n. 4, p. 23-31, jul./ago. 1994.

FERNANDEZ, Pablo. Company valuation methods: The most common errors in valuation. Madrid: IESE Business School, 2001.

GALDI, Fernando Caio; TEIXEIRA, Aridelmo José Campanharo; LOPES, Alexsandro Broedel. Análise Empírica de Modelos de Valuation no Ambiente Brasileiro: fluxo de caixa descontado versus modelo de Ohlson (RIV). Revista Contabilidade e Finanças, São Paulo, v. 19, n. 47, p. 31-43, ago. 2008. 
GOULART, Marselle. Como encontrar o valor de uma empresa: um enfoque teórico sobre os modelos de avaliação. Revista do Conselho Regional de Contabilidade do Rio Grande do Sul, Porto Alegre, n. 98, p. 56-66, out. 1999.

HELFERT, Erich A. Técnicas de Análise Financeira. Porto Alegre: Bookman, 2000.

KAPLAN, Steven N.; RUBACK, Richard S. The valuation of cash flow forecasts: an empirical analysis. Journal of Finance, Salt Lake City, Utah, v. 50, n. 4, p. 1059-1093, Sept. 1995.

KOBORI, José. Análise Fundamentalista: como obter uma performance superior e consistente no mercado de ações. Rio de Janeiro: Elsevier, 2011.

LEMME, Celso Funcia. Revisão dos modelos de avaliação de empresas e suas aplicações nas práticas de mercado. Revista de Administração, São Paulo, v. 36, n. 2, p. 117-124, jun. 2001.

LIMA M. V. A. et al. Avaliação de Micro e Pequenas Empresas Utilizando a Metodologia Multicritério e o Método do Fluxo de Caixa Descontado. Revista de Ciências da Administração, Santa Catarina, v. 12, n. 26, p. 48-71, jan./abr. 2010.

LUEHRMAN, T. A. Using APV: A Better Tool for Valuing Operations. Harvard Business Review, Cambridge, p. 145-154, maio/jun. 1997.

MARTELANC, R. et al. Utilização de Metodologias de Avaliação de empresas: Resultados de uma pesquisa no Brasil. I. In: Assembléia Anual Cladea, 34., 2005, São Paulo. Anais... São Paulo: USP, 2005. Disponível em: <http://www.ead.fea.usp.br/Semead/8semead/resultado/trabalhosPDF/315.pdf >. Acesso em: 25 nov. 2014.

MARTELANC, R.; PASIN, R.; PEREIRA, F. Avaliação de empresas: um guia para fusões \& aquisições e private equity. São Paulo: Pearson Prentice Hall, 2010.

MARTINS, E.; ASSAF NETO, A. Avaliação de Empresas: da mensuração contábil à econômica, Cadernos de Estudos FIPECAFI. FIPECAFI, São Paulo, n. 24, p. 28-37, jul./dez. 2000.

MARTINS, Eliseu. Avaliando a empresa (I). IOB, São Paulo, Boletim 10/98, 1998. Temática Contábil, p. 1-6.

MARTINS, Eliseu. Avaliação de empresas: da mensuração contábil à econômica. Caderno de Estudos FIPECAFI, São Paulo, v. 13, n. 24, p. 28-37, 2000.

MENDOZA, Barry Cuellar. Gestão do valor nas empresas num contexto de risco: estudo de caso de uma empresa do setor não cíclico de alimentos da Bovespa. Dissertação (Mestrado em Administração) - Universidade de São Paulo, São Paulo, 2008.

MIRANDA, G. J.; REIS, E. A. dos; LEMES, S. Valor de Empresas: uma abordagem do fluxo de caixa descontado. Contabilidade Vista \& Revista, Belo Horizonte, v. 17, n. 3, p. 45-65, jul./set. 2006.

OTTOSSON, E.; WEISSENRIEDER, F. Cash Value Added - a new method for measuring financial performance. [1996]. Disponível em: <http://papers.ssrn.com/sol3/papers.cfm?abstract_ id=58436 $>$. Acesso em: 8 dez. 2014.

PENMAN, S. H. Discussion. of "On Accounting-Based Valuation Formulae" and "Expected EPS and EPS Growth as Determinants of Value". Review of Accounting Studies, Columbia University, New York, v. 10, 2005.

RAPPAPORT, A. Gerando valor para o acionista. São Paulo: Atlas, 2001.

ROSA JÚNIOR, Dustran Machado. Avaliação de empresas: um estudo em uma instituição financeira. Dissertação (Mestrado em Engenharia de Produção) - Universidade Federal de Santa Catarina, Florianópolis, 2003.

SAURIN, V.; COSTA JUNIOR, N. C. A. da; ZÍLIO, A. da C. S. Estudo dos modelos de avaliação de empresas com base na metodologia do fluxo de caixa descontado: Estudo de caso. Revista 
Ciências da Administração, Florianópolis, v. 9, n. 18, p. 123-148, maio/ago. 2007.

SAURIN, V.; MIRANDA, A. L. P.; COSTA JUNIOR, N. C. A. Comparação dos Modelos de Avaliação de Empresas com Base no Fluxo de Caixa Descontado e no Lucro Residual: Estudo de caso de uma empresa de energia elétrica. Revista de Administração Mackenzie, São Paulo, v. 10, n. 1, p. 89113, fev. 2009.

SOUTES, D. O. et al. Métodos de avaliação utilizados pelos profissionais de investimento.

Contabilidade, Gestão e Governança, Brasília, v. 11, n. 1-2, p. 1-17, 2008.

VAN HORNE, J. C. Financial management and policy. 10. ed. New Jersey: Prentice Hall, 1995. 